\title{
Evaluation of Malaria Parasitemia Among HIVIAIDS Individuals Attending the Bamenda Regional Hospital Treatment Center
}

\author{
Eyong Clinton Achere ${ }^{1}$, Kechia Federick Agem ${ }^{1}$, Tembe Fokunang Estella ${ }^{2}$, Tatang Collins Asaah ${ }^{3}$, \\ Wandum Gangdia Carlson ${ }^{1}$, Agbor Michael Ashu ${ }^{4}$, Mbanya Dora Shu ${ }^{1}$, \\ Fokunang Charles Ntungwen ${ }^{2}$,
}

${ }^{1}$ Department of Biomedical Sciences, Faculty of Health Sciences, the University of Bamenda, Bamenda, Cameroon

${ }^{2}$ Department of Pharmaco-Toxicology \& Pharmacokinetics, Faculty of Medicine and Biomedical Sciences, University of Yaoundé 1, Yaoundé, Cameroon

${ }^{3}$ Department of Surgery and Specialties, Faculty of Medicine and Biomedical Sciences, University of Yaoundé 1, Yaoundé, Cameroon

${ }^{4}$ Department of Dentistry, Faculty of Health Sciences, University of Bangante, Bangante, Cameroon

Email address:

charlesfokunang@yahoo.co.uk (F. C. Ntungwen)

${ }^{*}$ Corresponding author

\section{To cite this article:}

Eyong Clinton Achere, Kechia Federick Agem, Tembe Fokunang Estella, Tatang Collins Asaah, Wandum Gangdia Carlson, Agbor Michael Ashu, Mbanya Dora Shu, Fokunang Charles Ntungwen. Evaluation of Malaria Parasitemia Among HIV/AIDS Individuals Attending the Bamenda Regional Hospital Treatment Center. Central African Journal of Public Health. Vol. 5, No. 2, 2019, pp. 65-76. doi: 10.11648/j.cajph.20190502.12

Received: January 12, 2019; Accepted: February 14, 2019; Published: February 28, 2019

\begin{abstract}
Malaria parasitemia and HIV/AIDS coinfection is very common particularly in sub-Saharan Africa where the burden of both infections fall. Therefore, an understanding of how the two infections interact is important for the control of both diseases. In Cameroon some studies have been carried out on the prevalence of malaria parasitemia in HIV with varying results. A high prevalence of malaria parasitemia among these individuals could imply the need for systematic screening and/or treatment of HIV individuals for possible malaria infection hence improving on the care of these individuals. A low prevalence could also imply limiting resources directed towards the diagnosis of malaria in HIV individuals. Objectives: The objective of the study was to determine the prevalence of malaria parasitaemia in HIV/AIDS individuals in Bamenda Regional Hospital (BRH) Treatment Center. Methods: A cross-sectional study was conducted involving $310 \mathrm{HIV}$-positive individuals attending the BRH HIV/AIDS Treatment Centre during a period of 3 months from 1st of February to April 30th 2018. Participants' consent was obtained followed by sociodemographic and other useful data via a standardized questionnaire. Capillary blood samples were collected and malaria parasitaemia determined by blood smear microscopy. Results: An overall malaria parasitemia prevalence of $24.5 \%$ was observed in this study with mean parasite density of 150 trophozoites $/ \mu \mathrm{L}$. Malaria parasitemia prevalence was significantly higher in HAART naïve $(37.5 \%)$ individuals than HAART experienced $(23.81 \%)$ individuals $(p<0.05)$. The differences in level of parasite density in relation to gender and marital status were statistically significant $(p<0.05)$ while that of the various age groups was not significant $(p<0.05)$. Lower CD4 count levels were significantly related to high density malaria parasitemia $(p<0.05)$. Also the percentage of parasite density $>400$ trophozoites $/ \mu \mathrm{L}$ was higher $(80 \%)$ in those not using cotrimoxazole prophylaxis than those on cotrimoxazole prophylaxis $(20 \%)$. Hence non- use of cotrimoxazole prophylaxis was significantly associated with high density malaria parasitemia $(p<0.05)$. Conclusions The prevalence of malaria parasitemia in HIV/AIDS individuals was high in the study area and malaria parasitemia prevalence in HAART naïve individuals was significantly higher than in HAART experienced individuals. Also gender, marital status low CD4 count and non use of cotrimoxazole prophylaxis were significantly related to high density malaria parasitemia.
\end{abstract}

Keywords: Malaria Parasitemia, HIV/AIDS, HAART, Prevalence 


\section{Introduction}

Worldwide, millions of individuals living with HIV reside in areas where malaria parasitemia is endemic and malaria is a leading cause of morbidity among individuals infected with HIV in sub-Saharan Africa [1]. An interaction in either direction between the two is therefore of great public health importance, particularly for sub-Saharan Africa where the majority of the burden of both infections fall. Growing evidence suggests a detrimental synergy between these two infectious diseases. Among adults living in malaria-endemic areas, HIV-related immune suppression seems to increase vulnerability to malaria parasitemia [1]. Several reports have shown that HIV infection among adults living in areas of high malaria transmission is associated with a modest increase in the frequency of malaria parasitemia [2]. Therefore, coinfection with HIV and malaria parasitemia is very common in sub-Saharan Africa and an understanding of how the two infections interact is important for the control of both diseases.

HIV infection can increase the risk and severity of malaria parasitemia and the increased parasite density might facilitate higher rates of malaria transmission. In areas of high endemicity, a majority of individuals with parasitemia may be asymptomatic owing to the development of partial immunity [3, 4]. These asymptomatic carriers retain the ability to transmit disease $[5,6]$ and create a reservoir of parasites that drives transmission. Older studies involving a range of African populations have reported that HIV infection is associated with an increased risk of malaria parasitemia [7-9]. These associations tend to be stronger with increasing levels of immunosuppression $[9,10]$. However, many of these studies were conducted before the wide spread use of combination antiretroviral therapy (cART) and trimethoprim-sulfamethoxazole (TMP-SMX) prophylaxis. More recently, some studies have reported that TMP-SMX prophylaxis is associated with a lower risk of parasitemia among HIV-infected and exposed patients [11, 12] while others have reported no protection [13]. A study carried out in Southeastern Nigeria by Onyenekwe et al showed that malaria parasitemia prevalence among HIV/AIDs individuals was $18.9 \%$ [14].

In Cameroon, recent studies carried out in two different regions on malaria parasitemia and HIV co- infection has varying results. One of the studies carried out by Akenji et al. in Douala, showed that the prevalence of malaria parasitemia in HIV-positive individuals was $29.4 \%$ [15]. This is similar to that carried out by Tchinda et al still in Douala, which showed a prevalence of $24.79 \%$ [16]. Another study carried out by Njunda et al in Bamenda showed that the prevalence of malaria parasitemia in HIV-positive individuals was $2.24 \%$ which is remarkably different from the aforementioned two studies [17]. The objective of the study to determine the prevalence of malaria parasitemia and the level of parasite density in relation to sociodemographic characteristics, CD4 count and use of cotrimoxazole prophylaxis in HIV/AIDS individuals attending the Bamenda Regional Hospital Treatment Center.

\section{Materials and Methods}

\subsection{Study Area}

The study was carried out in Bamenda Regional Hospital (BRH) using the HIV/AIDS treatment center of the hospital. This center is the largest treatment center of the North west region of Cameroon and second largest in the country. It receives averagely about 4000-5000 HIV-positive individuals with about 15 newly diagnosed HIV positive individuals each month. The climate of Bamenda is humid throughout the year with rainy and dry seasons, running from mid-March to October and from November to mid-March respectively. Bamenda has a mean temperature of about $21^{\circ} \mathrm{C}$. The recent creation of many institutions of higher learning like The University of Bamenda has attracted people of all ethnic backgrounds seeking to further their educational careers. Thus the population of Bamenda has increased recently which can lead to more malaria parasite transmission by the vector. BRH HIV/AIDS treatment center was therefore, an ideal site to evaluate malaria parasitemia among HIV/AIDS individuals.

\subsection{Study Duration}

Data was collected for a period of 3 months from $1^{\text {st }}$ of February to $30^{\text {th }}$ of April 2018.

\subsection{Study Design}

It was a hospital based cross sectional prospective and analytical study.

\subsection{Study Population}

The target population participant was all HIV/AIDS individuals of both sexes of consenting age attending the Bamenda Regional Hospital treatment center within the study period.

\subsubsection{Inclusion Criteria}

HIV/AIDS individuals who gave their consent, on HAART and those not yet on HAART attending the Bamenda Regional Hospital treatment centre within the study period

\subsubsection{Exclusion Criteria}

Individuals who did not fulfill all inclusion criteria

\subsubsection{Sample Size Calculations}

Lorenz formula was used to calculate the minimum sample size of our study from the malaria parasitemia prevalence gotten by Tchinda et al in 2012 at Laquintinie Hospital in Douala. The prevalence was $24.79 \%$ [16]. Hence, using this value in the calculation of the sample size following Lorenz formula:

$$
n=Z^{2} p(1-p) e^{2}
$$


Where $\mathrm{n}$ : is the minimum sample size of the study, $\mathrm{Z}$ : the power of the study, $\mathrm{P}=$ prevalence of study in Douala $(\mathrm{p}=$ $24.75 \%$ ), for a $95 \%$ confidence level, $\mathrm{Z}=1.96$, e $=$ selected sample error margin 5\%.

This implied: $\mathrm{n}=1.96^{2} \times 0.2475(1-0.2475) 0.05^{2}$

$$
\mathrm{n}=286.19
$$

Thus this gave a minimum sample size of 287 participants

\subsubsection{Sampling}

Consecutive sampling was used

\subsection{Study Procedure}

Before beginning the study, the protocol was reviewed and approved by the Faculty of Health Sciences Institutional Review Board. An authorization was obtained from the North West Regional Delegation of Public Health, the Director of the Bamenda Regional Hospital and the doctor in charge of the BRH HIV/AIDS treatment centre. The principal investigator then underwent one week training on how to diagnose malaria using microscopy. This was done at the BRH laboratory. HIV-positive individuals presenting at the BRH HIV/AIDS treatment centre from Monday to Friday between 8 am and $3 \mathrm{pm}$ were approached. Written consent was obtained from these individuals with the objectives of the study and data collection procedure properly explained to them. The questionnaire was then administered to the participant by the principal investigator and other trained field assistants. This was to aid in the collection of information on the patient's demographic data, patient's present antiretroviral medication, use of cotrimoxazole prophylaxis, recent CD4 count level and others.

A blood sample was then collected from the individual as follows; Individual's finger was cleaned with cotton wool soaked in $70 \%$ alcohol. Two drops of capillary blood was collected on a glass slide after finger prick. Slides were prepared by the principal investigator. Thick and thin films were immediately prepared for each participant's blood sample collected. The slides were allowed to air dry. After drying, the thin films were fixed with absolute methanol with great precaution so that it did not touch the thick film. The thin film was allowed to air dry (fix) for 2 minutes [33]. Both thick and thin films were then stained with $10 \%$ giemsa stain for 10 minutes. This was done by placing the dried blood smears on two rods and flooded with the $10 \%$ diluted giemsa stain for 10 minutes. After this, the stain was then flushed off using clean water and then allowed to air dry on a drying rack. When the blood films were completely dried, a drop of immersion oil was applied to a suitably stained area. The blood smear was then placed under the 100x objective of a binocular microscope with built-in illumination for malaria parasite observation [33].

Ten fields were examined and depending on the level of parasitaemia, up to fifty fields were examined to determine the average number of trophozoites per high power field. The total number of parasites seen was divided by the number of fields examined to get the average number of trophozoites per high power field. The parasite density was then estimated by multiplying the average number of parasites per high power field by 500 [33]. The factor of 500 was used based on the fact that the volume of blood per high power field of a well prepared thick film is approximately $0.002 \mu \mathrm{L}$. Therefore the number of parasites per high power field multiplied by 500 would give the number of parasites/ $\mu \mathrm{L}$ of blood [33]. A blood sample was considered as negative when no parasite was observed after examining at least 50 high power fields [33]. A sample of the examined slides were re-examined by a laboratory scientist to confirm the diagnosis.

\subsection{Data Management and Analysis}

Data was imported to SPSS from excel spread sheet and analyzed using SPSS version 20. Demographic characteristics such as gender, age and sex were summarized into percentages. The hypotheses were subjected to Chi square analysis for significant statistical correlation. Values of $p<0.05$ were considered statistically significant.

\subsection{Ethical Considerations}

This study was undertaken after an ethical clearance approval Ref No 2017/0029H/UBa/IRB, by the Institutional Review Board of The University of Bamenda. Authorization from the Regional Hospital of 17/Jan/2018 and an administrative authorization from the Regional Delegation of Public Health of Ref 22/Jan/2018. Participation in the study was voluntary. Strict anonymity and confidentiality was maintained in the handling of patient's data by ensuring that only the principal investigator had access to data. No names were put on questionnaires. Prior to collection of data, all participants were fully schooled about the objective of the study and the procedures that they would go through in the process. There was strict respect of the Helsinki Declaration of the fundamental ethical principles of respect, beneficience, malefecience and minimum risk infliction on participants

\section{Results}

\subsection{Baseline Characteristics of Study Population}

As shown in table 1, it was observed that out of the 310 participants, a greater proportion $(72 \%)$ were females with just $28 \%$ males. Moreso, when the ages were categorised, it was found that most of the participants were aged from 21-40 years $(53 \%)$. While those who were of age less than 20 years were least frequent $(1 \%)$. It was further revealed that majority of the participants $(52 \%)$ were married with the least being divorced $(9 \%)$. 
Table 1. Baseline characteristics of study population.

\begin{tabular}{|c|c|c|c|c|}
\hline Parameter & Category & Sample number & Frequency & Percentages \\
\hline \multirow{2}{*}{ Gender } & Male & 310 & 87 & 28 \\
\hline & Female & 310 & 223 & 72 \\
\hline \multirow{4}{*}{ Age } & $\leq 20$ & 310 & 2 & 01 \\
\hline & $21-40$ & 310 & 164 & 53 \\
\hline & $41-60$ & 310 & 127 & 41 \\
\hline & $\geq 61$ & 310 & 17 & 05 \\
\hline \multirow{4}{*}{ Marital status } & Single & 310 & 87 & 28 \\
\hline & Married & 310 & 161 & 52 \\
\hline & Widow (er) & 310 & 34 & 11 \\
\hline & Divorced & 310 & 28 & 9 \\
\hline
\end{tabular}

\subsection{Distribution of the Study Population According to the Use of HAART Regimens, CD4 Count and Use of Cotrimoxazole Prophylaxis}

\subsubsection{Use of Highly Active Anti-Retroviral Therapy (HAART)}

Out of 310 participants, 294 (95\%) were on HAART as shown on figure 1. Also for those who were on HAART, 86\% which constitute the majority had been on HAART for more than six months as shown on figure 2 .

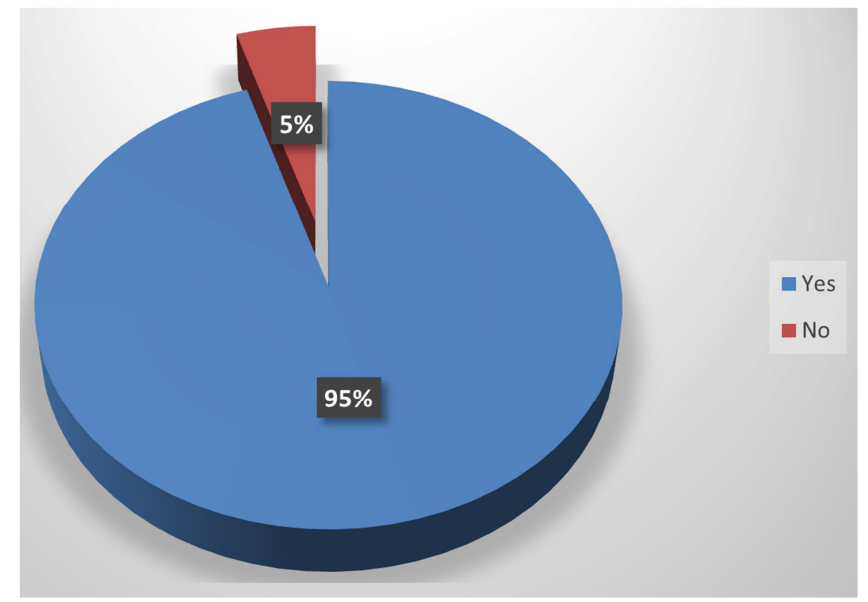

Figure 1. Distribution of the study population according to the use of HAART.

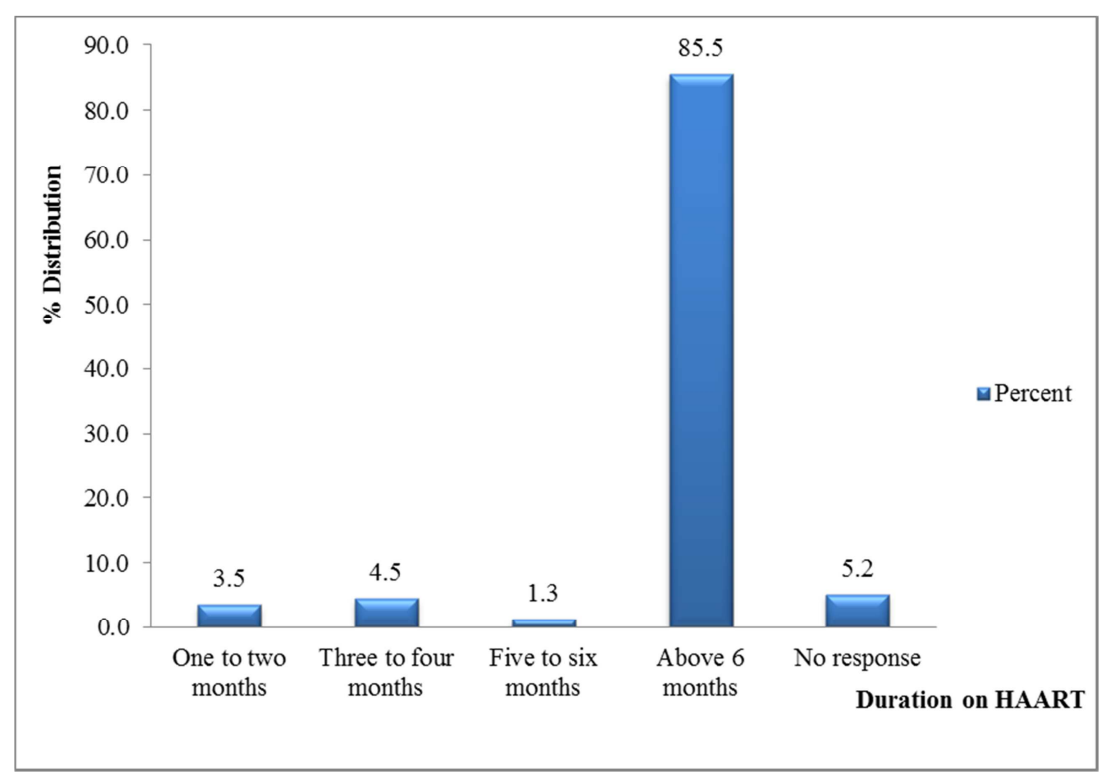

Figure 2. Distribution of the study population according to duration on HAART.

\subsubsection{HAART Regimens}

Out of the 294 participants who were on HAART, 252 (85.7\%) were on first line anti-retroviral therapy while $42(14.3 \%)$ were on second line anti-retroviral therapy. There was no participant on third line. Those on first line treatment were on a 
combination of Tenofovir, Lamivudine and Efavirenz while those on second line treatment took a drug combination of Tenofovir, Lamivudine and Indinavir as shown in figure 3.

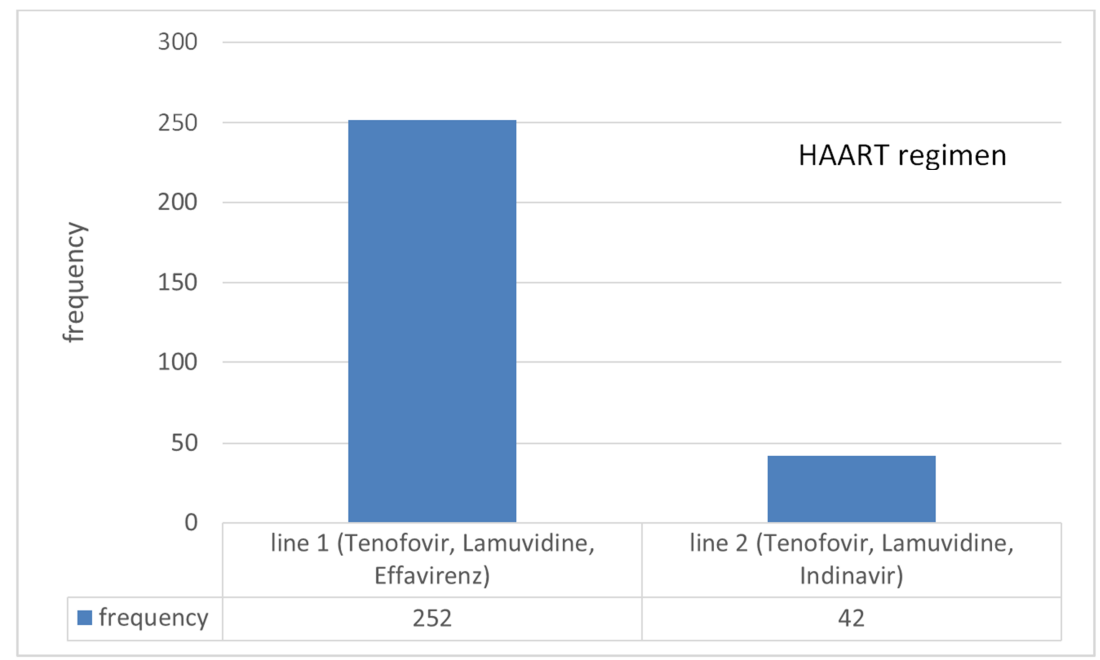

Figure 3. Distribution of HAART Regimens taken by participants.

\subsubsection{CD4 Count}

The CD4 counts of participants ranged from $<200$ to $>500$ cells $/ \mu \mathrm{L}$. As shown in figure 4 , a majority of the participants, 138 (45\%) had CD4 counts ranging from 200- 499 cells $/ \mu \mathrm{L}$. Those with CD4 counts $<200$ cells $/ \mu \mathrm{L}$ were least in number $(25 \%)$.

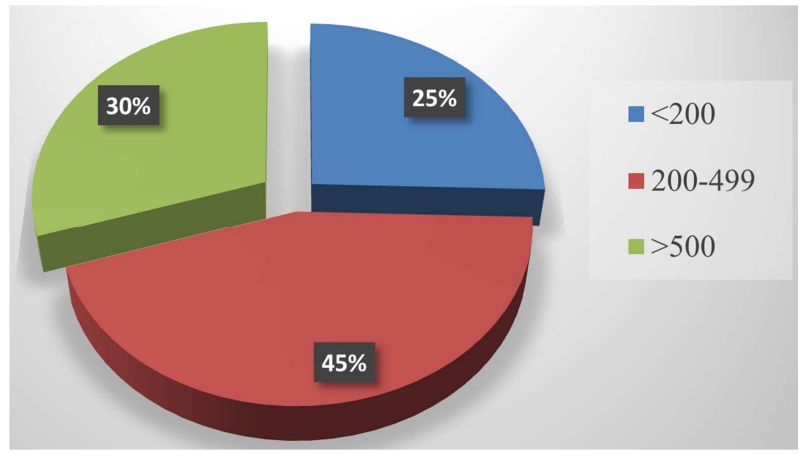

Figure 4. Distribution of the study population according to CD4 count levels.

\subsubsection{Use of Co-Trimoxazole Prophylaxis}

Out of 310 participants, 252 (81\%) were on Co-trimoxazole prophylaxis as shown in figure 5.

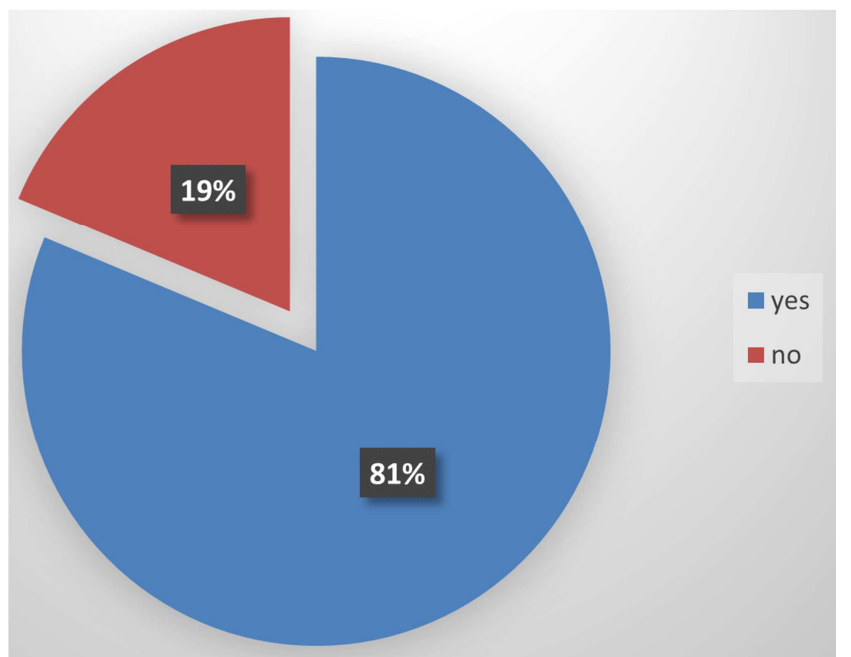

Figure 5. Distribution of study population by use of Co-trimoxazole prophylaxis. 


\subsection{The Prevalence of Malaria Parasitemia in the Study Population}

\subsubsection{The Overall Prevalence of Malaria Parasitemia in the Study Population}

Out of 310 participants enrolled in this study, 76 of them were positive for malaria arasitemia giving an overall prevalence of $24.5 \%$ as shown on figure 6 . The mean parasite density of these positive individuals was 150 trophozoites $/ \mu \mathrm{L}$ with values ranging from 100 to 600 trophozoites $/ \mu \mathrm{L}$.

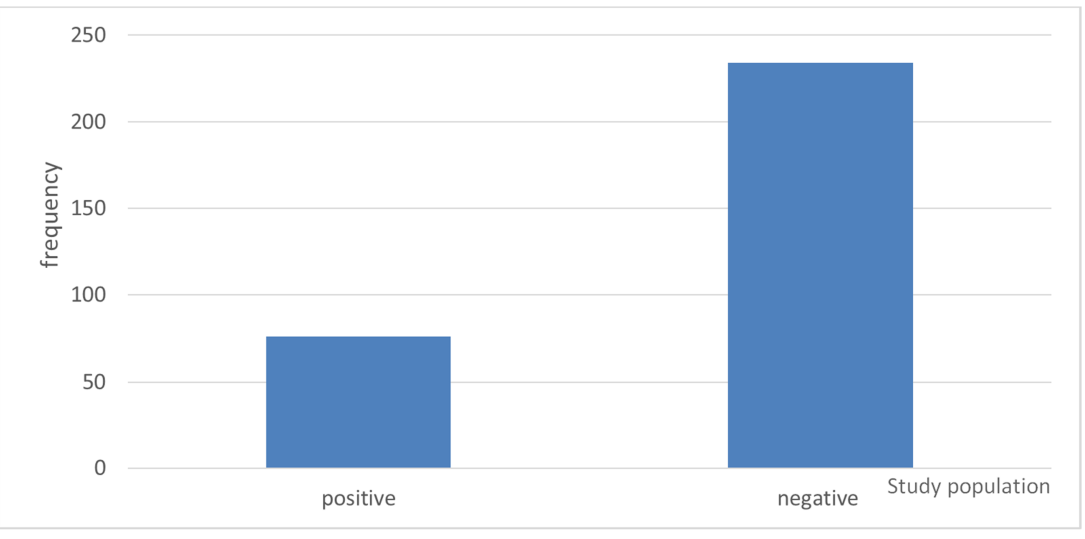

Figure 6. Distribution of malaria parasitemia in the study population.

\subsubsection{Comparing the Prevalence of Malaria Parasitemia Between HAART Experienced and HAART Nä̈ve Individuals}

Among 294 participants who were HAART experienced, 70 (23.81\%) were found to be positive for malaria parasitemia while $6(37.5 \%)$ out of the 16 HAART naïve individuals were positive for malaria parasitemia. This difference in the prevalence of malaria parasitemia between the two groups was statistically significant, $p<0.05$ as shown in table 2 .

Table 2. The prevalence of malaria parasitemia between HAART experienced and HAART naïve individuals $(n=76)$.

\begin{tabular}{|c|c|c|c|c|c|}
\hline Parameter & & HAART experienced & HAART naïve & $p$-value & Decision \\
\hline \multirow{2}{*}{ Gender } & Male & 18 & 2 & \multirow{2}{*}{0.013} & \multirow{2}{*}{ SIG } \\
\hline & Female & 52 & 4 & & \\
\hline \multirow{4}{*}{ Age } & $\leq 20$ & 0 & 0 & \multirow{4}{*}{0.000} & \multirow{4}{*}{ SIG } \\
\hline & $21-40$ & 33 & 2 & & \\
\hline & $41-60$ & 30 & 3 & & \\
\hline & $\geq 61$ & 7 & 1 & & \\
\hline \multirow{3}{*}{ Marital status } & Single & 19 & 1 & \multirow{3}{*}{0.000} & \multirow{3}{*}{ SIG } \\
\hline & Widow (er) & 7 & 1 & & \\
\hline & Divorced & 2 & 0 & & \\
\hline
\end{tabular}

$p<0.05$ was considered significant (SIG).

\subsubsection{Parasite Density for Positive Cases}

As shown in figure 7, majority of the participants $69(90.79 \%)$ had a parasite density of $<200$ trophozoites/ $\mu \mathrm{L}$ while those with parasite density from $200-400$ were least in number $(2.63 \%)$.

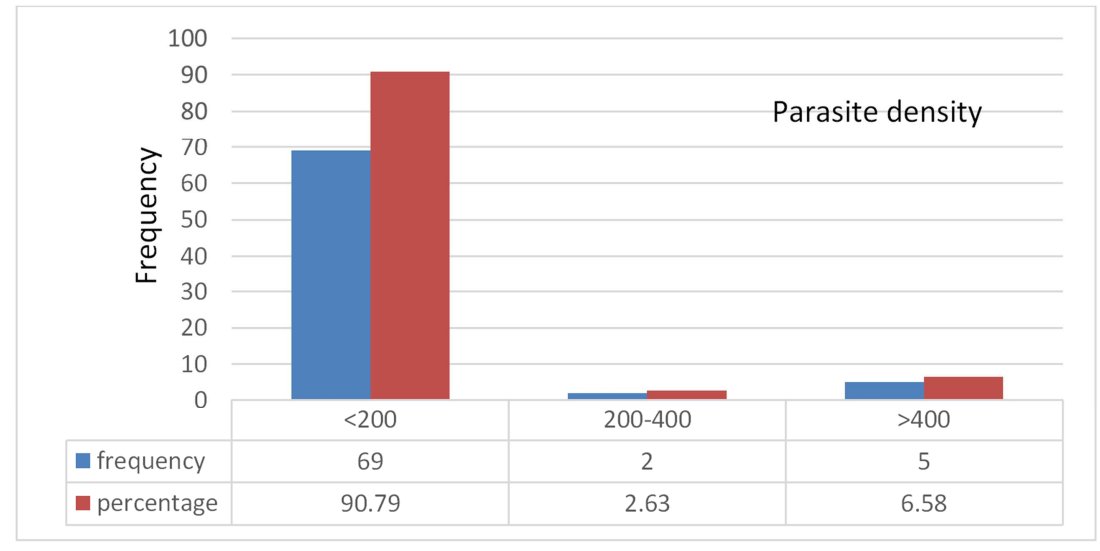

Figure 7. Distribution of parasite density for positive cases. 


\subsection{Malaria Parasite Density in Relation to Socio- Demographic Characteristics, CD4 Count and Cotrimoxazole Prophylaxis}

\subsubsection{Sociodemographic Characteristics}

As shown in table 6, females had higher parasite density ( $>400$ trophozoites $/ \mu \mathrm{L}$ ) than males. Also, out of 76 malaria parasitemia positive cases, there were more females $(71.1 \%)$ than males $(28.9 \%)$. The differences in the level of parasite density between male and female were statistically significant with $p<0.05$.

Those with ages from 21-40 years had higher number of malaria parasitemia positive cases $(46.1 \%)$ than the other age groups. The parasite density was also lower in this age group than those with ages from 41-60 years. However, the differences in the level of parasite density among the various age groups was not statisticallly significant with $p>0.05$.

Also as shown in table 3 , the number of positive malaria parasitemia cases as well as the level of parasite density was higher $(60 \%)$ in married individuals than singles. The differences in the level of parasite density in relation to marital status was considered statisticallly significant with $p<0.05$.

Table 3. The level of parasite density in relation to sociodemographic characteristics.

\begin{tabular}{|c|c|c|c|c|c|c|}
\hline Parameter & & Parasite Density & № of positive cases $n=76$ & Percentage positive & $p$-value & Decision \\
\hline \multirow{6}{*}{ GENDER } & & $<200$ & 21 & 27.6 & \multirow{6}{*}{0.021} & \multirow{6}{*}{ SIG } \\
\hline & Male & $200-400$ & 1 & 1.3 & & \\
\hline & & $>400$ & 0 & 0.0 & & \\
\hline & & $<200$ & 48 & 63.2 & & \\
\hline & Female & $200-400$ & 1 & 1.3 & & \\
\hline & & $>400$ & 5 & 6.6 & & \\
\hline \multirow{12}{*}{ Age } & & $<200$ & 0 & 0.0 & \multirow{12}{*}{0.104} & \multirow{12}{*}{ NS } \\
\hline & $\leq 20$ & $200-400$ & 0 & 0.0 & & \\
\hline & & $>400$ & 0 & 0.0 & & \\
\hline & & $<200$ & 32 & 42.1 & & \\
\hline & $21-40$ & $200-400$ & 1 & 1.3 & & \\
\hline & & $>400$ & 2 & 2.6 & & \\
\hline & & $<200$ & 29 & 38.2 & & \\
\hline & $41-60$ & $200-400$ & 1 & 1.3 & & \\
\hline & & $>400$ & 3 & 3.9 & & \\
\hline & & $<200$ & 8 & 10.5 & & \\
\hline & $\geq 61$ & $200-400$ & 0 & 0.0 & & \\
\hline & & $>400$ & 0 & 0.0 & & \\
\hline \multirow{12}{*}{ Marital status } & & $<200$ & 19 & 25 & \multirow{12}{*}{0.001} & \multirow{12}{*}{ SIG } \\
\hline & Single & $200-400$ & 0 & 0.0 & & \\
\hline & & $>400$ & 1 & 1.3 & & \\
\hline & & $<200$ & 42 & 55.3 & & \\
\hline & Married & $200-400$ & 1 & 1.3 & & \\
\hline & & $>400$ & 3 & 3.9 & & \\
\hline & & $<200$ & 6 & 7.9 & & \\
\hline & Widow (er) & $200-400$ & 1 & 1.3 & & \\
\hline & & $>400$ & 1 & 1.3 & & \\
\hline & & $<200$ & 2 & 2.6 & & \\
\hline & Divorced & $200-400$ & 0 & 0.0 & & \\
\hline & & $>400$ & 0 & 0.0 & & \\
\hline
\end{tabular}

$p<0.05$ was considered significant (SIG), $p>0.05$ was considered non significant (NS).

\subsubsection{CD4 Count}

As shown in table 4, It was observed that the percentage of parasite density $>400$ trophozoites $/ \mu \mathrm{L}$ was higher $(3.9 \%)$ with low CD4 count range $(<200$ cells $/ \mu \mathrm{L})$ when compared to the percentages $(0 \%)$ of high CD4 count range. Also the number of positive malaria parasitemia cases for low CD4 count range $(<200$ cells $/ \mu \mathrm{L})$ were higher $(47 \%)$ when compared to high CD4 count range ( $>500$ cells $/ \mu \mathrm{L})$. Hence, the results showed that low CD4 counts had higher parasite density. The differences in the level of parasite density among these CD4 count ranges was statistically significant with $p<0.05$.

Table 4. The level of parasite density in relation to CD4 count ranges.

\begin{tabular}{|c|c|c|c|c|c|}
\hline CD4 count range & Parasite Density & № of positive cases $(n=76)$ & Percentage positive & $p$-value & Decision \\
\hline \multirow{3}{*}{$<200$} & $<200$ & 32 & 42.1 & \multirow{3}{*}{0.053} & \multirow{3}{*}{ NS } \\
\hline & $200-400$ & 1 & 1.3 & & \\
\hline & $>400$ & 3 & 3.9 & & \\
\hline \multirow[t]{2}{*}{$200-499$} & $200-400$ & 1 & 1.3 & \multirow[t]{2}{*}{0.009} & \multirow[t]{2}{*}{ SIG } \\
\hline & $>400$ & 2 & 2.6 & & \\
\hline
\end{tabular}




\begin{tabular}{|c|c|c|c|c|c|}
\hline CD4 count range & Parasite Density & № of positive cases $(n=76)$ & Percentage positive & $p$-value & Decision \\
\hline \multirow{3}{*}{$>500$} & $<200$ & 12 & 15.8 & \multirow{3}{*}{0.032} & \multirow{3}{*}{ SIG } \\
\hline & $200-400$ & 0 & 0.0 & & \\
\hline & $>400$ & 0 & 0.0 & & \\
\hline
\end{tabular}

$p<0.05$ was considered significant (SIG), $p>0.05$ was considered non significant (NS).

\subsubsection{Use of Co-Trimoxazole Prophylaxis}

As shown in table 5, it was observed that although the number of positive malaria parasitemia cases were high $(64.4 \%)$ in those using Co-trimoxazole prophylaxis, the percentage of parasite density $>400$ trophozoites $/ \mu \mathrm{L}$ was higher $(80 \%)$ in those not using cotrimoxazole prophylaxis. Hence non- use of cotrimoxazole prophylaxis was associated with high density malaria parasitemia. The differences in the level of parasite density between these two groups was statistically significant with $p<0.05$.

Table 5. The level of parasite density in relation to Co-trimoxazole prophylaxis.

\begin{tabular}{|c|c|c|c|c|c|}
\hline Use of Cotrimoxazole prophylaxis & Parasite Density & No of positive cases $(n=76)$ & Percentage positive & $p$-value & Decision \\
\hline & $<200$ & 46 & & & \\
\hline \multirow[t]{2}{*}{ Yes } & $200-400$ & 2 & 64.4 & 0.000 & SIG \\
\hline & $>400$ & 1 & & & \\
\hline \multirow[t]{2}{*}{ No } & $200-400$ & 0 & 35.6 & 0.036 & SIG \\
\hline & $>400$ & 4 & & & \\
\hline
\end{tabular}

$p<0.05$ was considered significant (SIG).

\section{Discussion}

The clinical burden of malaria paraitemia and HIV/AIDS overlap widely in Cameroon [15] and are two of the most important health problems in the country [15]. Therefore, a poor clinical outcome is expected from their interaction. However, despite the increasing number of studies being carried out on these infections, there still exists discrepancy as to how common malaria parasitemia is among HIVpositive individuals. Thus a cross-sectional study of 310 participants was conducted with specific objectives being: to determine the prevalence of malaria parasitemia in HIVpositive individuals, compare the prevalence of malaria parasitemia between HAART experienced and HAARTnaïve individuals and to assess the level of parasite density in relation to siciodemographic characteristics, CD4 count and use of cotrimoxazole prophylaxis.

The results showed that the overall prevalence of malaria parasitemia in HIV/AIDS individuals attending the Bamenda Regional Hospital treatment center was $24.5 \%$ following microscopy from thick and thin blood films. This prevalence concurs with a previous study carried out by Tchinda et al in Douala, which showed a prevalence of $24.79 \%$ [16]. This was however higher when compared with the study carried out by Onyenekwe et al in southeastern Nigeria [14], where malaria prevalence among HIV-positive individuals was $18.9 \%$ and lower when compared to the study carried out by Akenji et al in 2008 at Nylon District Hospital located in the city of Douala, where the prevalence was $29.6 \%$ [15]. This discrepancy in findings could be attributed firstly to differences in geographical settings. The life cycle of the mosquito and the transmission dynamics of the diseases they transmit have been shown to be strongly influenced by climatic variables $[25,68]$. The development of the malaria parasite in the mosquito and rate of biting has also been shown to decrease at lower temperatures $[25,68]$. This is the case with our study where Bamenda although having a lower temperature altitude $\left(21^{\circ} \mathrm{C}\right)$ when compared to Douala $\left(27^{0} \mathrm{C}\right)$ which is at sea level [69] has recently become more populated due to the creation of many institutions of higher learning. Hence malaria transmission is expected to increase thus increasing the prevalence of malaria parasitemia in Bamenda. Secondly, these differences in prevalence could be due to differences in study designs as seen with that conducted by Akenji et al where they carried out a prospective cohort study as opposed to a cross-sectional study in our own case. This means their data is likely to be more valid than ours. Furthermore, the prevalence of malaria in our study $(24.5 \%)$ was far higher than that observed by Njunda et al (2.24\%) in Bamenda. Reasons for this could be that Bamenda has recently become more populated which favours more malaria transmission episodes than when Njunda et al carried out thier study. Moreover, this discrepancy could just be due to differences in study periods.

This study revealed that the prevalence of malaria parasitemia in HAART experienced individuals was $23.81 \%$ while the prevalence of malaria parasitemia in HAART naïve individuals was $37.5 \%$. This difference in the prevalence of malaria parasitemia between HAART experienced and HAART naive individuals was statistically significant with $p<0.05$ suggesting that the use of HAART could reduce the prevalence of malaria parasitemia. This was consistent with what Mermin et al observed in Uganda [12] where they found in a prospective study that individuals on HAART had significantly lower prevalence of malaria parasitemia when compared to HAART-naïve persons. However, the findings in this study were contrary to previous studies carried out in Cameroon [15-17] and other sub- Saharan countries [65,66] which support the fact that HAART is not significantly associated with the prevalence of malaria parasitemia. Although findings in this study were consistent with those of Mermin et al in Uganda [12], there were differences in study 
designs as well as the HAART regimens used. They conducted a prospective cohort study as opposed to a crosssectional study in our case. Besides, many participants in their study were on a drug combination of stavudine, lamivudine and nevirapine as opposed to tenofovir, lamivudine and efavirenz in our case. This could possibly mean that irrespective of study design and HAART regimens, the use of HAART could reduce the prevalence of malaria parasitemia in HIV/AIDS individuals

Females had higher parasite density $(>400$ trophozoites $/ \mu \mathrm{L})$ with greater prevalence of malaria parasitemia $(71.1 \%)$ than males $(28.9 \%)$. The differences in the level of parasite density between male and female was statistically significant with $p<0.05$ suggesting that females are more prone to infection with malaria parasites than males. Similarly, the number of positive malaria parasitemia cases as well as the level of parasite density was higher $(60 \%)$ in married individuals than singles. The differences in the level of parasite density in relation to marital status was also considered statisticallly significant with $p<0.05$ suggesting that many of the married HIV/AIDS individuals are not using effective malaria preventive methods. However, the results were contrary with previous reports by Saracino et al [65] who showed that age, gender and marital status did not significantly affect the prevalence of malaria in HIVpositive individuals in Mozambique. Moreso, the differences in the level of parasite density among the various age groups was not statisticallly significant with $p>0.05$ concuring to findings of saracino et al [65].

Furthermore, this study showed that the percentage of parasite density $>400$ trophozoites $/ \mu \mathrm{L}$ was higher $(60 \%)$ with low CD4 count range $(<200$ cells $/ \mu \mathrm{L})$ when compared to the percentages $(0-40 \%)$ of high CD4 count ranges. The differences in the level of parasite density with low CD4 count ranges were statistically significant with $p<0.05$, suggesting that high density malaria parasitemia was related to low CD4 count. Thus lower CD4 cell count predisposes infected patients to malaria infection. This concurred with previous studies carried out by Mermin et al. [12] and Kimbi et al. [64]. They found that lower CD4 counts are significantly associated with a higher prevalence of malaria parasitemia as well as an increase in the number of severe malaria attacks among HIV- positive individuals [63, 64]. However, the study results were contrary with what Tchinda et al [16] observed in Douala, in which they did not find CD4 counts to be significantly associated with the prevalence of malaria parasitemia. This discrepancy could be due to differences in patient clinical characteristics, study designs or study settings.

Finally, this study showed that although the number of positive malaria parasitemia cases were high $(78 \%)$ in those using Co-trimoxazole prophylaxis, the percentage of parasite density $>400$ trophozoites $/ \mu \mathrm{L}$ was higher $(80 \%)$ in those not using cotrimoxazole prophylaxis. The differences in the level of parasite density between these two groups were statistically significant with $p<0.05$, suggesting that high density malaria parasitemia was related to non use of cotrimoxazole prophylaxis. Thus the active ingredients of cotrimoxazole (trimethoprim + sulfamethoxazole) may have some therapeutic effects against malaria parasites as demonstrated by some studies [70, 71]. The study findings concurred with other studies by Mermin et al [12] in Uganda, Saracino et $a \mathrm{l}$ [65] and Angaret et al [66] both in Mozambique, where they found the use of co-trimoxazole prophylaxis to be significantly associated with a lower prevalence of malaria parasitemia as well as less severe malaria attacks. However, this is contrary to what was observed by Akenji et al [15], Tchinda et al [16], and Njunda et al [17], all in Cameroon that failed to observe any significant association between Co-trimoxazole prophylaxis and prevalence of malaria parasitemia. It is worth noting that although in this study, cotrimoxazole prophylaxis was found to be significantly associated with a lower prevalence of malaria parasitemia just like in studies carried out by Mermin et al. [14] in Uganda, Saracino et al. [65] and Angaret et al. [66] both in Mozambique, there were differences in study designs. They conducted a prospective cohort study as opposed to a cross-sectional study in our case. This could possibly mean that irrespective of study design, Cotrimoxazole prophylaxis could reduce the prevalence of malaria parasitemia.

In Cameroon it has been reported that the clinical burden of malaria parasitemia is the cause of about $45-50 \%$ of all hospital consultations [15]. The findings obtained in this study may have been confounded by the choice of a hospitalbased population. However, it was easier to follow up patients in a hospital. In addition, convincing patients to participate in an HIV-related study was quite challenging. A major limitation of the study was the very few number of HIV naive individuals since most of the participants are initiated on HAART immediately when tested HIV positive. It would have been desirable to have equal number of HAART experienced and HAART naïve individuals to increase the power and reliability of our findings.

\section{Conclusion}

From the findings in this study the overall prevalence of malaria parasitemia in HIV/ AIDS individuals was $24.5 \%$. The prevalence of malaria parasitemia was lower in HAART experienced compared to HAART naïve individuals. High density malaria parasitemia was related to sociodemographic characeristics (gender and marital status), low CD4 count and non-use of cotrimoxazole prophylaxis. Age was not found to be significantly associated to the level of parasite density.

\section{Author's Contributions}

Fokunang CN, Kechia AF Mbanya DS, conceived and designed the survey and supervised data collection and analysis; Eyong CA, Tatang CA, Wandum CG, collected the data, Tembe FE, Agbor MA, analysed data wrote the manuscript.

All authors made significant contributions to the 
manuscript and approved the final version for submission.

\section{Competing Interests}

The authors declare that they have no competing interests.

\section{Acknowledgements}

The authors are grateful to all the volunteer consented HIV/AIDS individual participants receiving treatment at the Bamenda Regional Hospital treatment center. The Director and the entire Staff of Regional Hospital Bamenda, especially the staff of the HIV/AIDS treatment center for their support and collaboration. The Dean, former Deans and the entire staff of the Faculty of Health Sciences of the University of Bamenda for the technical and material support. The Chantal Biya International Reference Centre for HIV/AIDS research for technical support.

\section{References}

[1] Molly F. Franke, Donna Spiegelman, Amara Ezeamama, Said Aboud, Gernard I. Msamanga, Saurabh Mehta and Wafaie Fawzi. Malaria Parasitemia and CD4 T Cell Count, Viral Load, and Adverse HIV Outcomes Among HIV-Infected Pregnant Women in Tanzania 2010. 09-0477.

[2] Hochman S, Kim K. The impact of HIV and malaria coinfection: what is known and suggested venues for further study. Interdiscip. Perspect. Infect. Dis. 2009, 617954.

[3] John CC, TandeAJ, MoormannAM et al. Antibodiestopreerythrocytic Plasmodium falciparum antigens and risk of clinical malaria in Kenyan children. J Infect Dis 2008; 197:519-526.

[4] Langhorne J, Ndungu FM, Sponaas A-M, Marsh K. Immunity to malaria: more questions than answers. Nat Immunol 2008; 9: $725-732$

[5] Bousema JT, Gouagna LC, Drakeley CJ, et al. Plasmodium falciparum gametocyte carriage in asymptomatic children in western Kenya. Malar J 2004; 3:18.

[6] Coleman RE, Kumpitak C, Ponlawat A, et al. Infectivityof asymptomatic Plasmodium-infected human populations to Anopheles dirus mosquitoes in western Thailand. J Med Entomol 2004; 41: 201-208.

[7] Cohen C, Karstaedt A, Frean J, et al. Increased prevalence of severe malaria in HIV-infected adults in South Africa. Clin Infect Dis 2005; 41: 1631-1637.

[8] Grimwade K, French N, Mbatha DD, Zungu DD, Dedicoat M, Gilks CF. HIV infection as a cofactor for severe falciparum malaria in adults living in a region of unstable malaria transmission in South Africa. AIDS 2004; 18: 547-554.

[9] Whitworth J, Morgan D, Quigley M, et al. Effect of HIV-1 and increasing immunosuppression on malaria parasitaemia and clinical episodes in adults in rural Uganda: a cohort study. Lancet 2000; 356: 1051-1056.

[10] Iroezindu MO, Agaba EI, Okeke EN, et al. Prevalence of malaria parasitaemia in adult HIV-infected patients in Jos,
North-central Nigeria. Niger J Med 2012; 21: 209-213.

[11] Sandison TG, Homsy J, Arinaitwe E, et al. Protective efficacy of co-trimoxazole prophylaxis against malaria in HIV exposed children in rural Uganda: a randomised clinical trial. BMJ 2011; 342: d1617.

[12] Mermin J, Ekwaru JP, Liechty CA, et al. Effect of cotrimoxazole prophylaxis, antiretroviral therapy, and insecticide-treated bednets on the frequency of malaria in HIV-1-infected adults in Uganda: a prospective cohort study. Lancet 2006; 367: 1256-1261.

[13] Noormahomed EV, Orlov M, do Rosario V, et al. A crosssectional study of subclinical Plasmodium falciparum infection in HIV-1 infected and uninfected populations in Mozambique, South-Eastern Africa. Malar J 2012; 11:252-259

[14] Onyenekwe CC, Ukibe N, Meludu SC, Ilika A, Aboh N, Ofiaeli N, Ezaeni M, Onochie A. Prevalence of malaria as coinfection in HIV-infected individuals in a malaria endemic area of Southeastern Nigeria. Journal of Vector Borne Disease. 2007; 44: 250-254.

[15] Akenji TN, Tevoufouet E, Nzang F, Ngufor N, Fon E. High prevalence of HIV and malaria co-infection in urban Douala, Cameroon. African Journal of AIDS Research. 2008; 7 (2): 229-235.

[16] Tchinda GG, Atashili J, Achidi EA, Kamga HL, Njunda AL, Ndumbe PN. Impact of malaria on hematological parameters in people living with HIV/AIDS attending the Laquintinie Hospital in Douala, Cameroon. PLoS One. 2012; 7 (7): e40553. doi: 10.1371/ journal. pone.0040553.

[17] Njunda LA, Kamga HL, Nsagha DS, Assob JC, Tebit EK. Low malaria prevalence in HIV-positive patients in Bamenda, Cameroon. Journal of Microbiology. 2012; 2 (3): 56-59.

[18] Anne Frances Gasasira. Interactions between HIV Infection and Malaria in Children Living in sub-Saharan Africa in the Era of Widening Access to Improved Interventions 20102 (3): $10-17$.

[19] A. C. Nwuzo1, O. Ogbu1, I. R. Iroha1, F. N. Afiukwa1, M. C. Ominyi4, A. C. Uhuo2 and M. E. Ogbanshi. The rate of distribution of malaria (Plasmodium falciparum) among HIV positive individuals visiting Saint Theresa's Hospital Abakpa Nike Enugu, Enugu State, Nigeria. European Journal of Experimental Biology, 2013, 3 (5): 516-520.

[20] WHO. World Malaria Report 2013. Geneva: World Health Organization, 2013, 312pp.

[21] Lia florey DHS Analytical Studies No. 43 Measures of Malaria Parasitemia Prevalence in National Surveys: Agreement between Rapid Diagnostic Tests and Microscopy. September 2014, 13: (2): 10-18.

[22] CDC - Malaria - About Malaria - Where Malaria Occurs [Internet]. [cited 2017 Apr 5]. Available from: https://www.cdc.gov/malaria/about/distribution.html.

[23] Francis EG Cox. History of the discovery of the malaria parasites and their vectors. Parasites \& Vectors. 2010; 3 (1). 21-29.

[24] Centers for Disease Control and Prevention. Malaria biology. Available at: http: // www.cdc.gov/malaria/about/biology/index.html. 201626 (1): 14-31. 
[25] WHO Global Malaria Programme. World Malaria Report 2014. Geneva, Switzerland: WHO Press; 2014, 35pp..

[26] L. Renia, S. M. Potter, et al. Co-infection of malaria with HIV: an immunological perspective. Parasite immunology. 2006; 28:589-595.

[27] Ian A Clark, Alison C Budd, Lisa M Alleva, William B Cowden. Human malarial disease: a consequence of inflammatory cytokine release. Malaria Journal. 2006; 5 (8): 312-317.

[28] Obi RK, Okangba CC, Nwanebu FC, Ndubuisi UU, Orji NM. Premunition in Plasmodium falciparum malaria. Afr J Biotechnol. 2010; 9 (10): 1397-1401.

[29] Laishram DD, Sutton PL, Nanda N, Sharma VL, Sobti RC, Carlton JM, et al. The complexities of malaria disease manifestations with a focus on asymptomatic malaria. Malar J. 2012 Jan 31; 11 (1): 29-35.

[30] Trampuz A, Jereb M, Muzlovic I, Prabhu RM. Clinical review: Severe malaria. Crit Care Lond Engl. 2003 Aug; 7 (4): 315-323.

[31] WHO. Management of severe malaria-A practical handbook. 2014, 205pp.

[32] WHO Criteria for Severe Falciparum Malaria [Internet]. [cited 2014 Mar 5]. Available from: http: //www.mymedal.org/index.php?n=Military.240107.

[33] Cheesbrough M. District Laboratory Practice In Tropical Countries. Part 1. Second Edition. Cambridge, UK: Cambridge University Press; 2009, 519pp.

[34] Centers for Disease Control and Prevention. CDC Treatment Guidelines for Malaria. Atlanta, United States of America: CDC; 2013, 115pp.

[35] Holmes CB, Losina E, Walensky RP, Yazdanpanah Y, Freedberg KA. Review of Human Immunodeficiency Virus type 1-related opportunistic infections in sub-Saharan Africa. Clinical Infectious Disease. 2003; 36: 652-662.

[36] Joint United Nations Programme on HIV/AIDS. UNAIDS Report on the global AIDS epidemic 2013. Geneva, Switzerland: WHO Press; 2013.

[37] World Health Organization. Global summary of the AIDS epidemic. Geneva, Switzerland: WHO Press; 2012, 41pp.

[38] Joint United Nations Programme on HIV/AIDS. UNAIDS 2013 Global fact sheet. Geneva, Switzerland: WHO Press; 2013., 107pp.

[39] Freed EO. HIV-1 replication. Somat Cell Mol Genet. 2001 Nov; 26 (1-6): 13-33.

[40] Kaslow RA, Phair JP, Friedman HB. Infection with the human immunodeficiency virus: clinical manifestations and their relationship to immune deficiency. A report from the Multicenter AIDS Cohort Study. Ann Intern Med. 1987; 107: 474-480

[41] Tebit DM, Ndembi N, Weinberg A, Quinones-Mateu ME. Mucosal transmission of human immunodeficiency virus. Curr HIV Res. 2012; 10 (1): 3-8.

[42] Gupta K, Menki L, Leostand D. Acute immunosuppression with HIV seroconversion. N Eng J Med. 1993; 32 (8): 288299.
[43] Chung A, Rollman E, Johansson S, Kent S., Stratov I. The utility of ADCC responses in HIV infection. Curr HIV Res. 2008; 8: 515-519.

[44] Brooks J KJ, Holmes K, Benson C, Pau A, Masur H. HIVassociated opportunistic infections-going, going, but not gone: the continued need for prevention and treatment guidelines. Clin Infect Dis. 2009; 48: 609-611.

[45] Fanales-Belasio E, Raimondo M, Suligoi B, Butto S. HIV virology and pathogenetic mechanisms of infection: a brief overview. Ann Ist Super Sanita. 2010; 46 (1): 5-14.

[46] Centers for Disease Control and Prevention. Revised Surveillance Case Definitions for HIV Infection Among Adults, Adolescents, and Children Aged $<18$ months and for HIV Infection and AIDS Among Children Aged 18months to $<13$ years. Atlanta, United States of America: CDC; 2008, $63 \mathrm{pp}$.

[47] Smith AJ, Daniel R. Following the path of the virus: the exploitation of host DNA repair mechanisms by retroviruses. ACS Chemical Biology. 2006; 1 (4): 217-226.

[48] Gilbert P. Comparison of HIV-1 and HIV-2 infectivity from a prospective cohort study in Senegal. Statistics in Medicine. 2003; 22 (4): 573-593

[49] Smith AJ, Daniel R. Following the path of the virus: the exploitation of host DNA repair mechanisms by retroviruses. ACS Chemical Biology. 2006; 1 (4): 217-226.

[50] Piatak M, Saag MS, Yang LC, Clark SJ, Kappes JC, Luk KC. High levels of HIV-1 in plasma during all stages of infection determined by competitive PCR. Science. 1993; 259 (5102): 1749-1754.

[51] Luft S, Seme K, Poljak M. Laboratory diagnosis of Human Immunodeficiency Virus infection. Acta Dermatoven APA. 2004; 13 (2): 45-49.

[52] Wilkins EGL. HIV Infection and AIDS. In: Nicki RC, Brian RW, Stuart HR. (eds.) Davidson's Principles and Practise of Medicine. 21st Edition. Edinburgh, UK: Elsevier Limited; 2010: p. $384-407$

[53] World Health Organisation. Consolidated guidelines on the use of antiretroviral drugs for treating and preventing HIV infection. Recommendations for a public health approach. Geneva, Switzerland: WHO Press; 2013, 25pp.

[54] World Health Organisation, in partnership with UNICEF and UNAIDS. Global update on HIV Treatment 2013: Results, Impact and Opportunities. Geneva, Switzerland: WHO Press; 2013, 93pp.

[55] Erick Kipkoech Rutto, Joshua Nyago, Julius Oyugi, Samson Ndege, Noel Onyango, Andrew Obala, Chrispinus J Simiyu, Gye Boor, Winfrida Chelangat Cheriro, Barasa Otsyula and Ben Estambale. Effects of HIV-1 infection on malaria parasitemia in milo sub-location, Western Kenya. 2015, 35pp.

[56] Anne Frances Gasasira. Interactions between HIV infection and malaria in children living in sub-Saharan Africa in the era of widening access to improved interventions 2010 45pp.

[57] Chandramohan D, Greenwood BM. Is there an interaction between human immunodeficiency virus and Plasmodium falciparum? International Journal of Epidemiology. 1998; 27 (2): 296-301. 
[58] Good MF, Doolan DL. Immune effector mechanisms in malaria. Current Opinion Immunology. 1999; 11: 412-419.

[59] Moore JM, Ayisi J, Nahlen BL, Misore A, Lal AA, Venkatachalam U. Immunity to placental malaria. II: Placental antigen-specific cytokine responses are impaired in human immunodeficiency virus-infected women. Journal of infectious diseases. Journal of infectious diseases. 2000; 182: 960-964.

[60] Froebel K, Howard W, Schafer JR, Howie F, Whitworth J, Kaleebu P. Activation by malaria antigens renders mononuclear cells susceptible to HIV infection and reactivates replication of endogenous HIV in cells from HIVinfected adults. Parasite Immunology. 2004; 26: 213-217.

[61] Tkachuk AN, Moormann AM, Poore JA, Rochford RA, Chensue SW, Mwapasa V. Malaria enhances expression of CC chemokine receptor 5 on placental macrophages. Journal of Infectious Disease. 2001; 183: 967-972.

[62] Kublin JG, Patnaik P, Jere CS, Miller WC, Hoffman IF, Chimbiya N. Effect of Plasmodium falciparum malaria on concentration of HIV-1 RNA in the blood of adults in rural Malawi: a prospective cohort study. Lancet. 2005; 365: 233240 .

[63] Cohen C, Karstaedt A, Frean J, Juno T, Govender N, Prentice E, Dini L, Galpin J, Crewe-Brown H. Increased prevalence of severe malaria in HIV-Infected adults in South Africa. Clinical Infectious Disease. 2005; 41 (11): 1631-1637.

[64] Kimbi HK, Njoh DT, Ndamukong KJN, Lehman LG. Malaria in HIV/AIDS patients at different CD4+ $\mathrm{T}$ cell levels in Limbe, Cameroon. Journal of Bacteriology and Parasitology. 2013; 4: 164-167.

[65] Saracino A, Nacarapa EA, Massinga AC, Martinelli D,
Scacchetti M, Oliveira C, Antonich A, Galloni D, Ferro JJ, Macome CA. Prevalence and clinical features of HIV and malaria co-infection in hospitalized adults in Beira, Mozambic. Malaria Journal. 2012; 11:241-246.

[66] Anglaret A, Patnaik R. Early chemoprophylaxis with trimethoprim/sulphamethoxazole for HIV-1 infected adults in Abidjan, Cote d'Ivoire: a randomized trial. Lancet. 2005; 353: $1463-1468$

[67] WHO (2008) Basic malaria microscopy: part I. Learner's guide, $\mathrm{p} 88$

[68] Reiter P. Global warming and vector-borne disease in temperate regions and at high altitude. Lancet. 1998; 351: 839-840.

[69] Pro-climate International. Climate of Cameroon. http://www.proclimate-international.org/ tourism/climate/cameroon.htm (accessed 5 Apr 2015).

[70] Wiktor SZ, Sassan-Morokro M, Grant AD, Abouya L, Karon JM, Maurice C, Djomand G, Ackah A, Domoua K, Kadio A, Yapi A, Combe P, Tossou O, Roels TH, Lackritz EM, Coulibaly D, De Cock KM, Coulibaly IM, Greenberg AE. Efficacy of trimethoprim-sulfamethoxazole prophylaxis to decrease morbidity and mortality in HIV-1-infected patients with tuberculosis in Abidjan, Cote d'Ivoire: a randomised controlled trial. Lancet. 1999; 353: 1469-1471.

[71] Hamel MJ, Greene C, Chiller T, Ouma P, Polyak C, Otieno K, Williamson J, Shi YP, Feikin DR, Marston B, Brooks JT, Poe A, Zhou Z, Ochieng B, Mintz E, Slutsker L. Does cotrimoxazole prophylaxis for the prevention of HIV-associated opportunistic infections select for resistant pathogens in Kenyan adults? American Journal of Tropical Medicine and Hygiene. 2008; 79: 320-322. 